\title{
Perspectives on Salutogenesis of Scholars Writing in Hebrew
}

\author{
Adi Mana, Sharón Benheim, and Shifra Sagy
}

\section{Introduction}

Aaron Antonovsky developed the salutogenic model during his years of work in the Israeli medical school at Ben Gurion University of the Negev, located in southern Israel, where he was one of the founders of the Faculty of Health. He left just a few researchers in his wake who continued in his path and paved the way for new research adapted to the diverse "social laboratory" that is the State of Israel. Today his salutogenic paradigm is widely spread over the world and is influential in Israel both in the area of research and in health and educational public policies.

The central salutogenesis work of Israeli researchers has been published in English to make it accessible to the international community who do not read Hebrew. Yet, there is a Hebrew salutogenesis literatureHebrew salutogenesis literature with a diversity of theoretical and empirical applications of the salutogenic model, embedded in the Israeli context and with the unique characteristics of this context.

In this review, we endeavor to encompass all of the work and most of the publications in Hebrew that have used Antonovsky's salutogenic model as a framework. We present the main directions of these studies and emphasize the unique characteristics of the research conducted in Israel.

In order to encompass the full extent of the research conducted in Israel, three databases of publications in

\footnotetext{
A. Mana $(\triangle)$

School of Behavioural Sciences, Peres Academic Center,

Rehovot, Israel

e-mail: manna.adi@gmail.com

S. Benheim

The Interdisciplinary Program of Conflict Management and

Reconciliation, Ben Gurion University of the Negev, Beer Sheva, Israel e-mail: Sharonjb@gmail.com

S. Sagy

Department of Education, Martin Springer Center for Conflict Studies, Ben-Gurion University of the Negev, Beer Sheva, Israel

e-mail: shifra@bgu.ac.il
}

Hebrew have been reviewed: The National Library of Israel, The National Institute for Research in the Behavioral Sciences, and The Haifa Key for Articles in Hebrew. From 1983 to 2014, there were 175 titles found that focus on the sense of coherence and the salutogenic model. Of those, 105 were master's theses and 19 were doctoral dissertations. Most of the research was conducted in the framework of the education departments $(37 \%)$, social work departments (34\%), and departments of psychology (19\%) of the various universities in Israel. The subjects of these studies were diverse in terms of age: starting with studies on kindergarten age children and continuing through research on senior citizens. Research participants came from many social groups including secular and religious, Arabs and Jews, immigrants from the Former Soviet Union and Ethiopia, and long-term Israeli citizens. Likewise, the research was diverse in terms of the types of life events they were dealing with. Topics have included coping with personal and individual events such as illness, hospitalization, burn out, and retirement, through to topics such as coping with interpersonal interactions, such as parenting and couplehood. Other work has focused on caring for a family member or a patient with special needs, and events at a community or country level such as being part of a problematic neighborhood, being part of a community being evacuated from its location (as part of governmental political decisions), coping with natural disasters, wars, and political violence.

Many of the research studies were conducted as theses and dissertations of graduate students. Some have been published in Israeli journals. Moreover, two volumes of Hebrew journals were dedicated to the salutogenic approach in Israel. The first volume in Megamot ("Trends" edited by Orr, Anson \& Sagy, 1998) included the last article by Antonovsky (translated by his son, Avishai). In the foreword to the article, he related to those who continue along his path:

"Theories, conceptual structures, hypotheses, and ideas are not sacred truths. All these must be related to as to fertilizing agents, 
heuristic starting points. The young researchers of today, looking back, tend to be impatient with what was yesterday exciting and productive for their senior colleagues. They tend to be unaware of the contribution made, to thought and research, and even to the breaking of new ground, by studies that with the passage of time became the basis of innovations, changes, and maybe even to a sharp turn in the field. They tend to minimize the importance of the knowledge that the present is the continuation of the past. With this, there are also those who remain stuck in the past, and find it hard to reconsider the knowledge, to update it, and move forward."

(Antonovsky, 1998, p. 170)

The second edited volume appeared 12 years later in Mifgash_Journal of Social Educational Work ("Meeting" edited by Sagy, 2010).

In this chapter, we review research studies which indeed contribute to the reconsideration of current knowledge, to updating the model, and to moving forward. From this review, it becomes clear that the model which Antonovsky developed more than 30 years ago continues to arouse the curiosity of researchers in Israel who are continuing to work within its paradigm, developing, and broadening it.

\section{Reassessment of Knowledge}

The salutogenic approach offers a different perspective and alternative assumptions than those of the pathogenic model which is more commonly used in social and health sciences. According to the salutogenic approach, which is similar to a great extent to the Buddhist perception which developed in the East, suffering and wearing down of the body are natural gradual processes in the lifetime of a human and are unavoidable. Humans, as living organisms, are a system with built-in inherent deficiencies along the continuum of "ease-dis-ease" and not on the dichotomous scale of healthy as opposed to ill. Antonovsky (1998) described this as coping with the dangerous river of life. While the pathogenic model focuses on the question "who or what pushed us into the river?" (focusing on identifying the risk factors and how to prevent them and advancing actions that benefit health in order to prevent or stop the illness). Antonovsky assumed that coping with the dangerous river is unavoidable and thus the question to ask is "how dangerous is the river and how good is our ability to swim?" Salutogenesis focuses on identification of the characteristics that allow "swimming in a dangerous river" and of the factors that help one develop and improve "swimming ability."

Generally, many of the research studies conducted in Israel compared between populations who coped with a specific stressful factor and similar populations who did not cope with that stressor. All the research studies used sense of coherence as a main salutogenic resource. The vast majority of the studies examined positive and negative stress outcomes and dealt with reinforcement of sense of coherence as a salutogenic basis.

Most of these research studies reinforced the theory about the relationship between sense of coherence and various measures of health and well-being. For example, a relationship between sense of coherence and adjustment was found among women with physical disabilities (Dangur, 1993), women with breast cancer (Kulik \& Kronfeld, 2003), and the social and emotional adjustment of chronically ill adolescents (Goldberg, Gutman, Sehada, \& Weissman, 2012). Sense of coherence was found to be related to relationships between sisters where one sister suffered from an eating disorder (Letzer, Katz, \& Berger, 2014) and to body image (Letzer, Spivak, \& Tzischinsky, 2013), to the development of a sense of leadership among social activists (Levy, Itzhaky, Zanbar, \& Schwartz, 2012), to a sense of well-being among Arab and Ethiopian single mothers (Roshke-Lazubar, 1999; Shwartzman, 1999), and to positions such as willingness for placement of a child out of the home among parents (Raif, 1997). Sense of coherence was also observed to be related to youth's attitudes about the use of drugs and alcohol (Elfassi, 2011; Sagy, 2011), to variables such as social acceptableness, worthiness, and hope among students with learning disabilities (Margalit, 2014) and to coping with acculturation stress (Rubinstein, Mirsky, Sharaga, \& Slonim-Nevo, 2010).

While the relationship between sense of coherence and variables of health and well-being were measured by various scales and surveyed in the context of many different aspects of the life of the subjects, the measures of negative stress outcomes were based mainly on the pathogenic model which measures psychological distress such as anxiety, stress, tension, depression, anger, and fatigue as well as symptoms of posttraumatic stress syndrome (David, 2010; Drori \& Florian, 1998; Erlich, 1997). These differences can be understood by the different characteristics of the pathogenic and salutogenic models. Orr, Anson, and Sagy (1998) emphasized that in the salutogenic approach the dependent variable must be examined as a measure of the experience of the individual on the continuum from poor health to good health. Thus, the determination of what is health is subjectively determined by the researcher, based on what is accepted in his/her holistic social world view and is varied and broad. This decision is substantially different from the determination of what is illness, which is derived from the pathogenic model with its list of defined and commonly accepted negative consequences of stressors. It seems as though thinking in the conceptual framework of the salutogenic model has encouraged researchers to broaden their view of coping and adaptation. 


\section{Studies Which Update Knowledge and Move It Forward}

From all the interesting studies which have employed the salutogenic model, two branches of research have been chosen for this review, which, in our opinion, have made a significant contribution to updating salutogenic knowledge and moving the field forward. In this chapter, we summarize studies which focus on two distinct main areas: research broadening the concept of sense of coherence from the individual level to wider levels of analysis such as the family and the community or even the national level, and research focusing on sense of coherence amongst children with learning disabilities.

\section{Sense of Coherence on the Personal and Collective Level}

As a sociologist, Antonovsky (1998) ascribed great importance to the structural factors and circles of influence on the sense of coherence from the individual level to the group and community levels.

The central question about how such structural resources contribute to the development of SOC has focused on the family system. What are the resources in the family for a strong sense of coherence? Antonovsky and Sagy proposed this question to the Israel Scientific Fund just before he passed away. Sagy and Helen Antonovsky continued this line of research (Sagy \& Antonovsky, 1999, 2000) and later other studies were conducted (e.g., Bental, 2001; Bental \& Sagy, 2010). These studies (Bental, 2001; Bental \& Sagy, 2010; Sagy \& Antonovsky, 1998) combined quantitative and qualitative methodologies. Several types of family life experiences, for example, participating in decision making, experience of consistency, emotional bond, balance in emotional load, and sense of belonging were found as resources for developing strong sense of coherence in later life.

Besides the question of collective resources as contributing to SOC, salutogenic research in Israel has also examined the sense of coherence in ever widening circles: relationships between parent and child, relationships between members of a couple, families, communities, and other intergroup relationships. The relationship between the level of an individual's sense of coherence and his/her perception of the family framework has interested many researchers. Strong correlations have been found between level of individual sense of coherence and other variables such as family atmosphere (Navon, Feigin, \& Drori, 2001), tensions in parental functioning (Goldberg \& Weisman, 2010; Strenger, 1997), and family support (Sarir, 2012; Shwartzman, 1999). These studies confirm the hypothesis that positive family relationships correlate with high levels of coherence among family members and contribute to coping with stress factors.

Another way to study the family level was to develop measures to examine the level of the family sense of coherence as a collective measure. Sourani (1983) and Sagy (1990) developed such family measures of sense of coherence under the supervision of Antonovsky. Sourani (1983) studied a measure among disabled men relating to the spouses separately and asked about their perceptions of their family coherence. She found a correlation between the men's sense of coherence of family life and their spouses' perceptions.

Sagy (1990) studied the family as a social system. She compared four alternative collective measures: the average of sense of coherence of spouses, the highest measure between the spouses (the salutogenic measure), the lowest measure (the pathogenic measure), and the gap between the spouses' SOC. The results indicated that the salutogenic version of family SOC (the highest score among family members) was a better predictor of adaption than the individual sense of coherence (Sagy \& Antonovsky, 1998).

The assumption that there is a sense of coherence at the level of the system, which is different than that of the individuals that make up that system, has been examined later in wider social contexts (Sagy, 2014), like neighborhoods or communities (Elfassi, 2011: Peled, 2014; Srour, 2015).

For about 30 years, Sagy and her colleagues and students have tried to explain the relatively high mental health findings of Israeli youth, as compared with youth in the rest of the world. In spite of their living in the shadow of the violent and intractable conflict, uncertainty, and serious social gaps, the indicators of wellness and health are basically high. Based on the salutogenic model, coping resources were studied among youth from different social groups experiencing local and national chronic and acute crises. Examples include life under missile fire (Braun-Lewensohn \& Sagy, 2010; Edelman, 2013; Peled, 2014), before and after the evacuation from Yamit in Sinai (Sagy, 1986) and from Gush Katif in the Gaza Strip (Galili \& Sagy, 2010; Sagy, 2006), house destruction in the Bedouin unrecognized villages (Al Said, 2015), the second Intifada (Wirtsberger, 1997), the Lebanon war (Benzion, Shahrabani, \& Shavit, 2010; Green, Lavi, \& Dekel, 2010; Sagy \& BraunLewensohn, 2014), and more.

Sagy (2014) summarized the findings as follows:

- Most youth in Israel cope well with stress. The level of distress reactions or other reactions like anxiety and anger, change according to the situation, but are moderate over time, as compared to emotional reactions of youth in other parts of the world. 
- The levels of their emotional reactions are not related to the level of exposure to the stress factor.

- The personal and family resources of sense of coherence are most important in understanding the reaction to stress, even if the source of stress is at the collective-political level.

- Most of the groups studied in the different Israeli samples displayed a relatively high individual and family sense of coherence.

- Significant differences were found between various populations within Israel with regard to level of sense of coherence. For example, sense of coherence was lower among economically weaker populations (Elfassi, 2011) and secular populations were found to have lower community sense of coherence as compared to religious groups (Galili \& Sagy, 2010; Srour, 2015).

- One of the interesting differentiations found in these research studies was the difference between reactions of youth in chronic stress situations, and chronic stress situations with an acute element (Edelman, 2013; Sagy \& Braun-Lewensohn, 2014). In the chronic situations, the intensity of the reaction was mostly explained by personal sense of coherence. However, in the chronic situations which had an acute element, the ability of personal factors to explain emotional reactions was weakened. The understanding of reactions in those situations was possible by looking at the collective community reaction (Sagy, 1986). This finding has important practical implications regarding interventions in a variety of situations (Sagy \& Braun-Lewensohn, 2014).

Sagy (2014) concludes her summary of these years of research employing salutogenesis with a proposal for a new direction which expands the sense of coherence to the national level. She notes that the Israeli society's strong collective sense of coherence allows the collective in Israel to move toward growth and health despite the stressful Israeli reality. While wondering about the price of the strong national sense of coherence, she asks, "Does the strong national sense of coherence also enable us to hear the narrative of the 'other,' or even to get to know the 'other' or feel empathy toward the 'other's' suffering?" Her question about a possible correlation between strong national sense of coherence and low openness toward the "other" (and low readiness to reconcile) breaks ground and broadens the salutogenic model in new research directions which are currently being investigated by doctoral students. Recent survey research (Sagy, Ayalon, and Srour, 2015) indeed confirms this direction.

\section{Students with Learning Disabilities and the Salutogenic Model}

The research conducted in Israel that has established a connection between students with learning disabilities and salutogenic variables is an example of the type of research that Antonovsky hoped to promote-research based on the concept of sense of coherence, which contributes systematically to programs and which is intended to strengthen comprehensibility, manageability, and meaningfulness for a particular population (Antonovsky, 1998). While the pathogenic model emphasizes a learning disability's negative impact on learning functioning, Margalit (2014) emphasized the emotional-social-environmental aspect in understanding the importance of promoting developmental processes, and the mental health of students with learning disabilities. In an extensive review article, Margalit (2014) reviewed 15 years of the research on the neurodevelopmental model of learning disabilities. In her review, she focused on the contribution of the integration between different theoretical approaches to understand the difficulties and the challenges that children and adults with learning disabilities have to face. Based on the salutogenic model, Margalit emphasized the need to identify the strengths, the personal, interpersonal and environmental resources instead of focusing on the difficulties and disabilities. She also rejected the dichotomy scale between ability and disability and perceived a more dynamic continuum scale. According to the salutogenic model, the educational purpose is not to "heal" the disabilities but to find the way to strengthen the individual's social and learning adjustment.

In the studies of Margalit and her colleagues, sense of coherence was found to be one of the scarce resources, yet its importance for this population is central. It was found that already by kindergarten age, children at risk of developing learning disabilities reported a lower sense of coherence as compared to their peers (Levin Al-Yagon, 2000). A similar trend was found among children with learning disabilities in elementary school and in adolescence (Margalit, 2000a; Sharabi \& Margalit, 2009; Ziv, 2004). Consistent negative correlations were found between sense of coherence and loneliness (Margalit, 1997; Neuberger \& Margalit, 1998), and learning helplessness (Margalit, 1983), and positive correlations were found between sense of coherence and hope, self-efficacy, and friendship (Margalit, 2014). These studies point out that learning disabilities influence overall personal development.

Margalit and her colleagues (2014) identified a small group among the population of children with learning disabilities who have succeeded in showing resilience in the emotional and social areas as compared with their 
peers. This group of children displayed stubbornness and consistent effort to fight against being different and against the difficulties they faced. That resilience was found to be connected to personal characteristics: higher level of sense of coherence, hope, and extroversion (Margalit \& TurKaspa, 1998; Neuberger \& Margalit, 1998) and to environmental, family, and educational characteristics such as mothers' and fathers' sense of coherence, family solidarity, and students' perceptions of the teacher as a "secure base."

Intervention programs (Margalit, 2000a; Sharabi \& Margalit, 2012) and an important report which was adopted by the Israeli Ministry of Education (Margalit, 2000b) have been based on the idea that children with learning disabilities need to function according to their abilities in the regular school system as much as possible. These ideas emerged from the salutogenic paradigm. It appears that salutogenic thinking in the era of learning disabilities is consistently seeping into research, and from there into the public discourse and educational policies in Israel (Margalit, 2000a).

\section{Conclusion}

The violent conflictual reality in Israel, rich in stressful situations, is a fertile and fascinating "social laboratory" for researchers. The repeated findings among Israeli children, adolescents, and adults indicate high levels of sense of coherence and resilience despite the ongoing stressful situation of wars, terror, and violent conflicts (Elran, 2006; Sagy, 2014). What is this "secret" of the Israeli society, which helps it to face the challenges and difficulties?

Exchanging the pathogenic questions about the emotional and physical cost of life in the stormy Israeli reality into salutogenic questions has revealed some solid answers. This review of the salutogenic research in Israel seems to emphasize the resources found in many studies that enable many individuals in Israel to move toward growth and health in spite of this difficult reality, and maybe even because of it. Perhaps, it is mainly the strong meaningfulness and the feelings of comprehensibility and manageability that strengthen the durability and adaptive ability of people living in conflict areas. However, the picture is not complete without relating to the cost of this strong sense of coherence and high resilience measures. In order to cope with the results of living in a prolonged violent reality, a psychological repertoire evolves (Bar Tal, 2007). Thus, another direction of salutogenic research has recently been advanced in the conflictual Israeli reality which leads to the study of national sense of coherence in relation to openness toward the "other" and readiness to reconcile (Sagy, 2014; Sagy, Ayalon, \& Srour, 2015).
Open Access This chapter is distributed under the terms of the Creative Commons Attribution-Noncommercial 2.5 License (http:// creativecommons.org/licenses/by-nc/2.5/) which permits any noncommercial use, distribution, and reproduction in any medium, provided the original author(s) and source are credited.

The images or other third party material in this chapter are included in the work's Creative Commons license, unless indicated otherwise in the credit line; if such material is not included in the work's Creative Commons license and the respective action is not permitted by statutory regulation, users will need to obtain permission from the license holder to duplicate, adapt or reproduce the material.

\section{References (translated from Hebrew)}

Al Said, H. (2015). Stress reaction, coping resources and collective identity among Bedouin Arab adolescents exposed to demolition of houses: Comparison between adolescents living in different kinds of villages (recognized and unrecognized villages). Doctoral dissertation, Ben Gurion University of the Negev, Beer Sheva.

Antonovsky, A. (1998). The Salutogenic model as a guiding theory in health promotion. Megamot, 65, 170-181.

Bar Tal, D. (2007). Living with the conflict: Sociopsychological analysis of the Jewish society in Israel. Jerusalem: Carmel.

Bental, A. (2001). Structural sources of the sense of coherence: A narrative analysis of life stories. Doctoral dissertation, Ben Gurion University of the Negev, Beer Sheva.

Bental, A., \& Sagy, S. (2010). Life experiences contributing to the development of a sense of coherence: Consistency and/or background experience? Studies in Education. Iyunim Bahinuch, 1-2, 215-241.

Benzion, U., Shahrabani, S., \& Shavit, T. (2010). Emotions and perceived Risks among young people after the 2006 Israeli-Lebanon war. Mifgash: Journal of Social —Educational Work, 31, 115-138.

Braun-Lewensohn, O., \& Sagy, S. (2010). Stress reactions and coping resources among Jewish and Bedouin adolescents during 'Oferet Yetzuka' (Operation Cast Lead) and six months later. Mifgash: Journal of Social-Education Work, 31, 13-31.

Dangur, N. (1993). The relationship between stress factors, tension, and coping resources and between the emotional/psychological and family coping among women with and without physical disabilities. Doctoral dissertation, Bar-Ilan University School of Social Work, Ramat Gan.

David, E. (2010). The sense of coherence and health among Holocaust survivors. Doctoral dissertation, University of Haifa, Haifa.

Drori, Y., \& Florian, V. (1998). Sense of coherence and mental health profile in first myocardial infarction patients. Megamot, 39, 116-117.

Edelman, A. (2013). Sense of coherence and hope as explanatory factors of stress reactions among adolescents exposed to missile fire: Chronic stress vs. acute-chronic stress. Doctoral dissertation, Ben-Gurion University of the Negev, Beer-Sheva, Israel.

Elfassi, Y. (2011). Relationship between adolescents' perception of their communities as a source of coping resources and their sense of coherence and patterns of exposure to and involvement in violence and drug abuse. Doctoral dissertation, Ben-Gurion University of the Negev, Beer-Sheva, Israel.

Elran, M. (2006). Israel's natural resilience: The influence of the second Intifada on Israeli society. Tel Aviv University: Jaffe Center for Strategic Studies.

Erlich, N. (1997). Burn-out among professionals rehabilitation workers and para-professional. In A. Rimerman, M. Hovav, A. Duvduvani, \& A. Ramot (Eds.), Developmental disabilities with mental 
retardation in Israel: Needs and solutions (pp. 251-266). Jerusalem, Israel: Magnes.

Galili, R., \& Sagy, S. (2010). Stress reactions among religious and secular adolescents in Gush Katif: A salutogenic approach. Mifgash: Journal of Social-Education Work, 31, 139-159.

Goldberg, A., Gutman, H., Sehada, N., \& Weissman, H. (2012). Adolescents with juvenile diabetes: Sense of coherence as a mediator between quality of self-treatment and diabetic balance. The Israeli Journal for Pediatric Medicine, 78, 34-36.

Goldberg, A., \& Weisman, H. (2010). Parents' sense of coherence and resolution with child's chronic disease to promote the physical and mental health of adolescents with type 1 diabetes. Mifgash: Journal of Social-Educational Work, 32, 31-52.

Green, O., Lavi, T., \& Dekel, R. (2010). Growing pains: Israeli adolescents one year after the Second Lebanon. Mifgash: Journal of Social-Educational Work, 31, 35-59.

Kulik, L., \& Kronfeld, M. (2003). Prediction of coping/adaptation with breast cancer: The contribution of personal resources and attribution of the reason for the illness. Society \& Welfare: Social Work Quarterly, 23(1), 75-100.

Letzer, Y., Katz, R., \& Berger, K. (2014). Psychological distress among sisters of young females with eating disorders: The role of negative siblingship and sense of coherence. Society \& Welfare, 34, 358.

Letzer, Y., Spivak, Z., \& Tzischinsky, O. (2013). The relationship between sense of coherence, body image, and disordered eating among adolescent girls: Identifying groups at risk. Mifgash: Journal of Social-Educational Work, 38, 31-54.

Levin Al-Yagon, M. (2000). Emotional, social and behavioural adjustment among kindergartners at risk for developing Learning disorders. Doctoral dissertation, Tel Aviv University, Tel Aviv.

Levy, D., Itzhaky, H., Zanbar, L., \& Schwartz, C. (2012). Sense of cohesion among community activists engaging in volunteer activity. Society \& Welfare, 32, 551.

Margalit, M. (1983). Sense of coherence and learner-helplessness in the learning disability syndrome. Studies in Education, 37(38), 153-158.

Margalit, M. (1997). Loneliness among children with mental retardation: Individualistic and systemic perspectives. In I. Duvdevani, M. Hovav, A. Rimerman, \& A. Ramot (Eds.), Parenthood and developmental disability in Israel (pp. 133-150). Jerusalem, Israel: Magnes.

Margalit, M. (2000a). Learning Disabilities in the classroom: Educational dilemmas in new realities. Tel-Aviv, Israel: Mofet Institute.

Margalit, M. (2000b). The Margalit Report. Retrieved from http://info. smkb.ac.il/home/home.exe/2148/12285, http://info.smkb.ac.il/ home/home.exe/2148/12285

Margalit, M. (2014). Learning disabilities: A neuro-developmental model-After 15 years. Mifgash, 39, 13-32.

Margalit, M., \& Tur- Kaspa, H. (1998). Learning disabilities: A Neurodevelopmental multidimensional model. Psychology, 7(1), 64-76.

Navon, S., Feigin, R., \& Drori, M. (2001). Breaking through: Family coping with illness \& disability, psychosocial intervention models. Tel Aviv, Israel: Ramot.

Neuberger, S., \& Margalit, M. (1998). Coherence, loneliness, and social competence of children with special educational needs. Megamot, 39, 128-148.

Orr, E., Anson, O., \& Sagy, S. (1998). Prologue: The salutogenic approach as an initiator of a dynamic scientific production. Megamot, 39, 9-18.

Peled, D. (2014). Coping with rocket fire: The community as a buffering factor in reducing emotional distress. Doctoral dissertation, Ben Gurion University of the Negev, Beer Sheva.
Raif, R. (1997). Level of willingness for out of home placement among parents of pre-school children with developmental disabilities. In A. Duvduvani, M. Hovav, A. Rimerman, \& A. Ramot (Eds.), Parenting and disabilities in Israel. Magnes: Jerusalem, Israel.

Roshke-Lazubar, S. (1999). The Arab single-parent family in Jaffo: The influence of social support, sense of coherence, and positions on single parenting, on sense of well-being, in comparison to the Jewish single-parent family. Doctoral dissertation, Haifa University School of Social Work: Haifa.

Rubinstein, L., Mirsky, J., Sharaga, Y., \& Slonim-Nevo, V. (2010). Risk and resilience factors among immigrant adolescents from the former Soviet Union. Mifgash: Journal of Social-Educational Work, 31, 201-219.

Sagy, S. (1986). Adolescents' reactions to a stress situation: Before and after evacuation of the Sinai settlements. M.A. thesis, Ben-Gurion University of the Negev, Beer-Sheva, Israel.

Sagy, S. (1990). The family sense of coherence and adjustment to stressors. Doctoral dissertation, Ben-Gurion University of the Negev, Israel.

Sagy, S. (2006). Between evacuation and disengagement: Israeli adolescents coping with changing political reality. Academia, 16, $17-25$.

Sagy, S. (2010). Special Issue: Israeli youth and children coping with stress in a conflictual reality-The salutogenic approach in research and practice. Mifgash: Journal of Social-Educational Work, 31, $8-14$.

Sagy, S. (2011). Preventing use of psychoactive materials among children and adolescents: Where does the Salutogenic model take us? Israeli Journal of Education and Health Promotion, $4,26-31$.

Sagy, S. (2014). Salutogensis: Notes from the diary of a conflict researcher in the "safe room" during "Operation Cloud Pillar.". Mifgash: Journal of Social-Educational Work, 40, 9-27.

Sagy, S., \& Antonovsky, A. (1998). Sense of coherence in the family system: The salutogenic orientation. Megamot, 39, 80-89.

Sagy, S., \& Antonovsky, H. (1999). Structural resources contributing to the development of Sense of Coherence: Analysis of life stories. Sichot: The Israeli Journal of Psychotherapy, 14(1), 51-56.

Sagy, S., \& Antonovsky, H. (2000). The development of the sense of coherence: A retrospective study of early life experiences in the family. International Journal of Aging \& Human Development, 51, 155-166.

Sagy, S., Ayalon, A., \& Srour, A. (2015). National sense of coherence and attitudes towards reconciliation. Hamidgam Project.

Sagy, S., \& Braun-Lewensohn, O. (2014). Coping resources and stress reactions among adolescents under rocket fire: A comparison between acute and chronic stress situations. Megamot, 49, 754-774.

Sarir, E. (2012). The relationship between readiness for change and sense of coherence and family support, among Heroin addicts. Doctoral dissertation, Tel Aviv University School of Social Work, Tel Aviv.

Sharabi, A., \& Margalit, M. (2009). Learning disabilities among the young in Israel. In I. Levav (Ed.), Psychiatric and behavioral disorders in Israel. Gefen: Jerusalem, Israel.

Sharabi, A., \& Margalit, M. (2012). Transition planning from school to work for youth with disabilities. Jerusalem, Israel: Ministry of Social Affairs.

Shwartzman, O. (1999). The Ethiopian single-parent family: The influence of the support system and sense of coherence on personal sense of well-being. Doctoral dissertation, Haifa University School of Social Work, Haifa. 
Sourani, T. (1983). Sense of family coherence and influence on adaption of families. M.A. thesis, University of Haifa School of Social Work, Haifa.

Srour, A. (2015). Sense of community coherence, collective narrative perceptions and openness to the "other" group: The case of Muslim-Christian relationships in Israel. Doctoral dissertation, Ben Gurion University of the Negev, Beer Sheva.

Strenger, V. (1997). Tension in the role of parenting and response to child among parents of children with congenital physical defects:
A literature review. In A. Duvduvani, M. Hovav, A. Rimerman, \& A. Ramot (Eds.), Parenting and disabilities in Israel (pp. 35-52). Jerusalem, Israel: Magnes.

Wirtsberger, I. (1997). Adolescents' reactions to a stress situation: Effects of personal and community factors. MA Thesis, Ben-Gurion University of the Negev, Beer-Sheva, Israel.

Ziv, A. (2004). Risk factors, defensive factors, coping methods, and adapting in upper school among pupils with learning difficulties/ disabilities. Doctoral dissertation, Tel Aviv University, Tel Aviv. 